\title{
Epidemiology, Race/Ethnic Origin
}

National Cancer Institute

\section{Source}

National Cancer Institute. Epidemiology, Race/Ethnic Origin. NCI Thesaurus. Code

C18773.

The consideration of race and/or ethnic orig in as variables in disease incident, transmission, and control. 